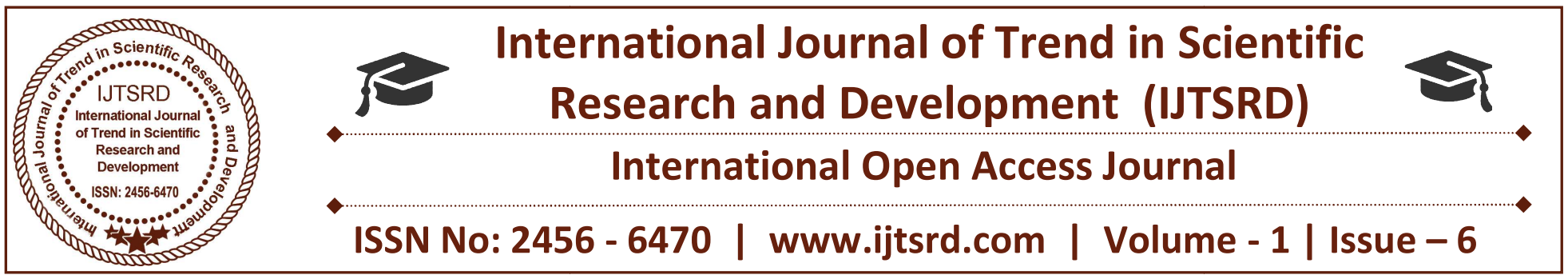

\title{
Lack of association between CD45 C77G polymorphism and multiple sclerosis in Kashmir
}

\author{
Insha Zahoor ${ }^{1 \#}$, Amrina Shafi ${ }^{2 a}$, Mudasir A Mir ${ }^{3 a}$
}

${ }^{1}$ Department of Biotechnology, Faculty of Biological Sciences, University of Kashmir, Hazratbal, J\&K, India.

${ }^{2}$ Division of Biotechnology, CSIR-Institute of Himalayan Bioresource Technology, Palampur, Himachal Pradesh, India.

${ }^{3}$ Centre for Plant Biotechnology, Division of Biotechnology, Sher-e-Kashmir University of Agricultural Sciences and Technology (SKUAST) Kashmir, Shalimar, J\&K, India.

E-mails: inshazahoor11@gmail.com, amrinashafi7@gmail.com,mudasirbt@gmail.com

${ }^{a}$ Both authors contributed equally

${ }^{\#}$ Corresponding author: Dr. Insha Zahoor (Tel.: +91-979-708-8530; E-mail: inshazahoor11@gmail.com)

\section{ABSTRACT}

Multiple sclerosis (MS) is a severe disabling and demyelinating disease of the nervous system. Its etiology involves profound genetic component. The latest contender known to have been correlated with $\mathrm{MS}$ is protein tyrosine phosphatase receptor-type $\mathrm{C}$ (PTPRC or CD45); however, to date its role remains contentious. The aim of the current study was to examine the association of functionally significant exon 4 C77G polymorphism of CD45 with MS in Kashmiri population from Indian subcontinent. The preliminary findings of our study revealed absence of $\mathrm{C} 77 \mathrm{G}$ in majority of the cases as well as controls. These findings strongly suggest that the alterations in CD45 are sporadically associated with the genesis of MS. In conclusion, results from our study are in accordance with some of the international studies; however, more studies with large datasets from Kashmir as well as other ethnic populations are warranted to validate the above preliminary findings and demonstrate the role of CD45 C77G polymorphism in MS pathogenesis.
Keywords: $\quad M S ; \quad$ genetics; $\quad C D 45 ; \quad C 77 G$; polymorphism; Kashmir

\section{INTRODUCTION}

Multiple sclerosis (MS) is a chronic autoimmune inflammatory disease which primarily affects central nervous system (CNS) of the body. Owing to its inexplicable etiology, it has been found to develop due to complex interactions between environmental and genetic factors; however, genetic components seem to play a major rule in its pathogenesis [1-3]. The variations in different candidate genes of MS play an important role in disease susceptibility [4]. By and large MS susceptibility has been linked to the Major Histocompatibility Complex (MHC) [5, 6], although there are other genes as well which have been found to be associated with its development [7, 8]. Incidentally, few previous studies have reported a polymorphism in exon 4 of protein tyrosine phosphatase receptor-type C (PTPRC or CD45), which results in replacement of $\mathrm{C}$ to $\mathrm{G}$ at nucleotide 77 [9-11]; albeit it is not conclusive and it has been complicated due to controversial data from some studies [12-15]. CD45 [OMIM 151460; Entrez Gene 
5788] is located on chromosome 1 at position q31.3q32.1 and belongs to the family of protein tyrosine phosphatase (PTP). It plays a critical role in regulating protein-tyrosine kinases involved in signal transduction thereby activating $\mathrm{T}$ and $\mathrm{B}$ cells $[16,17]$. Keeping in view its essentiality for the functioning of immune system, we investigated the association between CD45 and MS in an Indian population, covering the patients from Kashmir region.

\section{Materials and Methods}

\subsection{Study participants}

A total of 20 unrelated MS patients from Kashmir region of India were recruited for the present study from the In Patient Department (IPD) and Out Patient Department (OPD) of the Department of Neurology, Sher-I-Kashmir Institute of Medical Sciences (SKIMS), Soura, Kashmir, India; following the proper ethical procedures of the hospital. All the MS cases were relapsing-remitting (RR) type and diagnosis was made by the neurologist (RA) according to 2010 Revised McDonald Diagnostic criteria [18]. The local Institutional Ethics Committee of SKIMS reviewed and approved this study (No. SKIMS 1 31/IECSKIMS/2013-6380). Informed consent was acquired from all subjects prior to enrolment. All procedures performed with human participants and their samples were in accordance with the ethical standards of the institutional research committee and 1964 Helsinki declaration and its later amendments or comparable ethical standards.

\subsection{Blood sample collection and DNA extraction}

$2 \mathrm{ml}$ of whole peripheral venous blood was collected from the RRMS cases and controls in EDTA coated Vacutainer tubes (ADS Hitech Polymers, India) and stored at $-80^{\circ} \mathrm{C}$ before processing for DNA extraction. Blood samples were also collected from healthy individuals from the same geographic area to serve as controls. Genomic DNA was extracted from the blood leukocytes by using DNeasy® Blood \& Tissue Kit (Qiagen, Germany), according to the manufacturer's enclosed protocol and its integrity and specificity was checked on $0.8 \%$ agarose gel by comparing with $1 \mathrm{~kb}$ DNA ladder (Fermentas, USA). The concentration of extracted DNA samples was determined by using NanoDrop $^{\mathrm{TM}}$ Spectrophotometer (Thermo Fisher
Scientific, USA) and stored at $-20^{\circ} \mathrm{C}$ till further processing.

\subsection{CD45 amplification}

The amplification of CD45 exon 4 was performed using the newly designed primer sequences (Forward Primer: 5' GCAAAGATGCCCAGTGTTCC 3' and Reverse Primer:

5' TTGTGTGCCAACCTGTGGTA 3'). PCR was carried out in thermal cycler (Benchmark TC9639, USA), at respective annealing temperatures (Tm) of primer sets obtained after optimization, in a reaction volume of $50 \mu \mathrm{l}$ containing 50-100 $\mathrm{ng}$ of genomic DNA, $0.2 \mathrm{mM}$ dNTPs (Thermo Scientific, USA), 1x Phusion HF Buffer (New England Biolabs, Inc. USA), $1 \mathrm{U}$ of Phusion DNA Polymerase (New England Biolabs, Inc. USA) and $0.4 \mu \mathrm{M}$ of each primer (Imperial Life Sciences, India). Amplification was performed by initial denaturation at $98^{\circ} \mathrm{C}$ for $5 \mathrm{~min}$, followed by 30 cycles of denaturation at $98^{\circ} \mathrm{C}$ for 30 $\mathrm{s}$, annealing at $57^{\circ} \mathrm{C}$ for $45 \mathrm{~s}$, extension at $72^{\circ} \mathrm{C}$ for 1 min and a final extension at $72^{\circ} \mathrm{C}$ for $5 \mathrm{~min}$, after the last cycle. The specificity of amplified products was checked by analyzing on 1.5\% agarose gel and comparing with $100 \mathrm{bp}$ DNA ladder (Thermo Fisher Scientific, USA). Purification of PCR products was done by using the GenElute ${ }^{\mathrm{TM}}$ Gel Extraction Kit (Sigma-Aldrich, USA), according to the manufacturer's instructions and samples were then stored at $-20^{\circ} \mathrm{C}$ till sequencing.

\subsection{Sequencing}

For examining $\mathrm{C} 77 \mathrm{G}$ polymorphism in CD45, the amplified products were sequenced commercially through the services of SciGenom Labs, Pvt., Ltd., Kerala, India (http://www.scigenom.com). Nucleotide sequences of the amplicons were viewed and analyzed for alterations by comparing with NCBI reference sequence using ClustalX Version 2 [19, 20], Chromas $\begin{array}{llll}\text { Pro } & \text { Version } & 1.49 & \text { beta }\end{array}$ (http://www.technelysium.com.au) and Finch TV (http://www.geospiza.com). Databases such as Human Gene Mutation Database (HGMD; http://www.hgmd.cf.ac.uk), $\quad$ NCBI's $\quad$ SNP (http://www.ncbi.nlm.nih.gov/snp) and PubMed databases (http://www.ncbi.nlm.nih.gov/pubmed) were consulted for the detection of $\mathrm{C} 77 \mathrm{G}$. 


\section{Results and Discussion}

The present study comprised of 20 RRMS patients as well as controls from the Indian data set, covering the patients from its northern region Kashmir. All the subjects were of the Kashmiri ethnicity. Agarose gel electrophoresis revealed successful extraction of DNA from blood samples of both cases as well as controls (Fig. 1). The extracted DNA was used as a template for amplification of CD45 gene and PCR products on analysis showed specific bands on the agarose gel as per expected size of $199 \mathrm{bp}$ (Fig. 2). After analysis of sequence alignment and chromatograms of nucleotide sequences of samples, $\mathrm{C} 77 \mathrm{G}$ was found to be absent in cases as well as controls (Fig. 3).

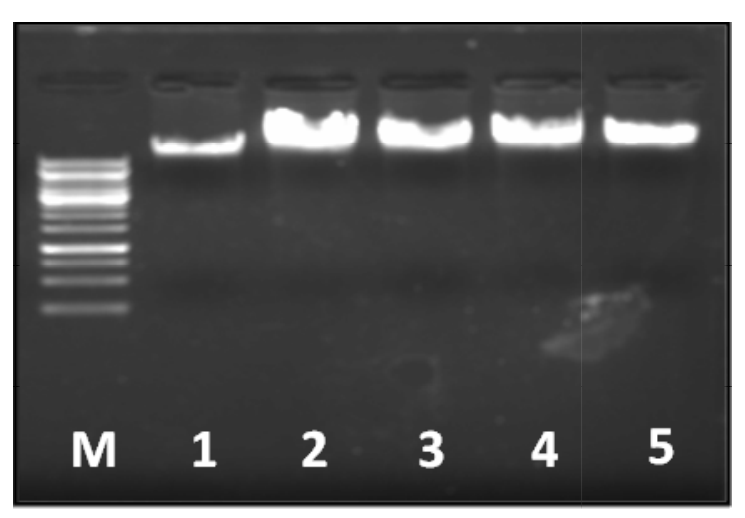

Figure 1. Representative $0.8 \%$ agarose gel showing DNA extracted from study subjects. $2 \mu 1$ (100-200 $\mathrm{ng} / \mu \mathrm{l})$ of each sample was loaded in each well. [Lane $\mathrm{M}$ shows separation pattern of $1 \mathrm{~kb}$ ladder; and lanes 1 to 5 show genomic DNA].

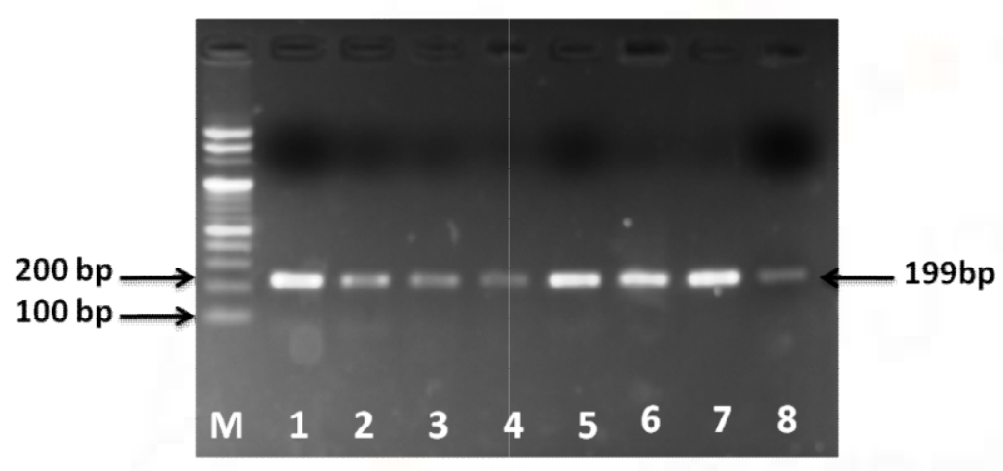

Figure 2. Representative 1.5\% agarose gel showing specific PCR amplification product of CD45 (199 bp) in study subjects. $2 \mu \mathrm{l}(100-200 \mathrm{ng} / \mu \mathrm{l})$ of each sample was loaded in each well. [Lane $\mathrm{M}$ shows separation pattern of $100 \mathrm{bp}$ ladder; and lanes 1 to 8 show desired product].

(a)

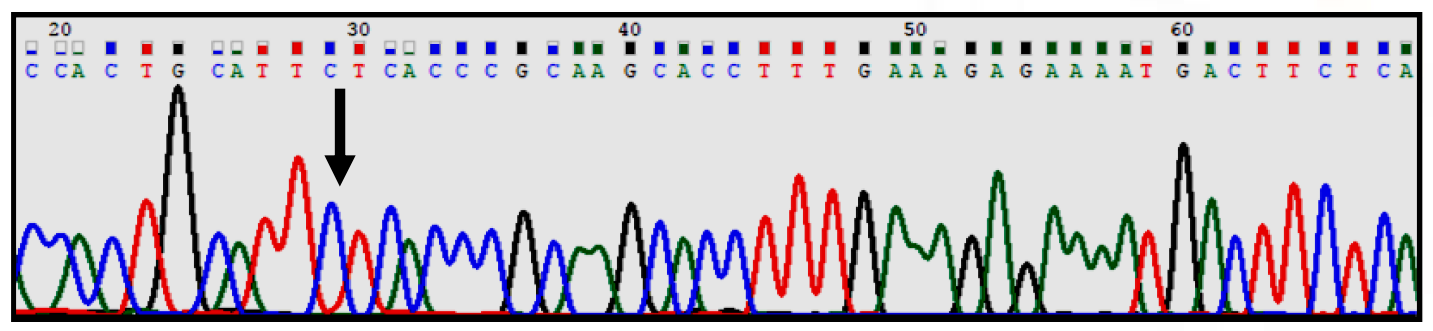

(b)

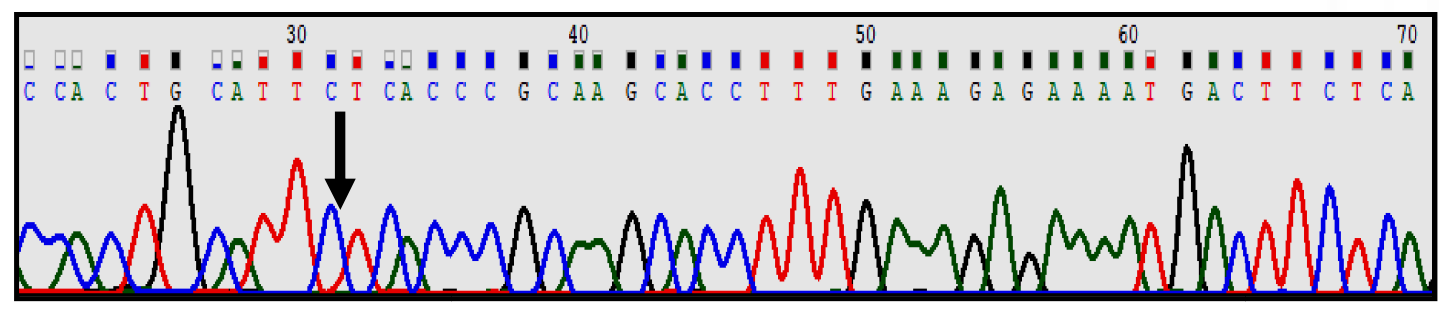

Figure 3. Representative sequence chromatograms showing the absence of CD45 C77G polymorphism in MS case (a) and control (b). 
The development of MS is a complex and multifactorial process mediated by various genetic and environmental factors involving numerous related pathways $[1,3,8,21]$. It has been seen that genetic alterations contribute to the genesis of MS [8]. To a large extent, progress has been attained in recognizing the candidate genes and gene defects that underlie inherited predisposition to MS. Therefore, screening

of MS candidate genes for genetic variations can further clarify the relationship between genetics of MS and its development. Even though there is paucity of reports on the association between MS and CD45, some previous studies have reported $\mathrm{C} 77 \mathrm{G}$ polymorphism in exon 4 of CD45 among MS patients from different ethnic backgrounds [9-11]. Keeping in view the association between $\mathrm{C} 77 \mathrm{G}$ polymorphism of CD45 with MS, we screened this variant in ethnic cohort of Kashmiri patients as our population being small, isolated, and containing conserved gene pool makes it a right candidate for gene analysis study. Sequence analysis indicated that no alteration exists in CD45 in MS patients from Kashmir valley of India. This study strongly suggests that alterations present in MS patients vary from population to population and it can be inferred that alterations found in one population may not be necessarily present in MS patients from other geographic area as both environmental as well as genetic factors influence MS development. Thus, it can be suggested that alterations in CD45 are infrequently associated with the genesis of MS and its association with MS susceptibility strongly depends on environmental factors.

\section{Conclusion}

To the best of our knowledge, this is the first study from India in which we examined the presence of C77G polymorphism in CD45 gene in Kashmiri population. Our preliminary findings clearly revealed absence of $\mathrm{C} 77 \mathrm{G}$ polymorphism in $\mathrm{MS}$ patients as well as controls. However, keeping in view primary limitation of our study due to very small sample size, it becomes mandatory to validate our findings by taking into account large datasets from Kashmir region of India.

\section{Acknowledgment}

We wish to express our deepest gratitude to all the subjects for their participation in this study. We are highly indebted to Dr. Ravouf Asimi, Additional Professor, Department of Neurology, Sher-I-Kashmir Institute of Medical Sciences (SKIMS), Soura, J\&K, India, for providing help in sample collection.

\section{Conflict of interest}

The authors declare no potential conflicts of interest with respect to the research, authorship and/or publication of this article.

\section{References}

1) G.C. Ebers, Environmental factors and multiple sclerosis. Lancet Neurol, 7, 268-77, 2008.

2) D.S. Goodin, The genetic basis of multiple sclerosis: a model for MS susceptibility. BMC Neurol, 10, 101, 2010.

3) S.V. Ramagopalan, R. Dobson, U.C. Meier, and G. Giovannoni, Multiple sclerosis: risk factors, prodromes, and potential causal pathways. Lancet Neurol, 9, 727-39, 2010.

4) A.D. Sadovnick, P.A. Baird, and R.H. Ward, Multiple sclerosis: updated risks for relatives. Am J Med Genet 29, 533-41, 1988.

5) J.R. Oksenberg, L.F. Barcellos, B.A. Cree, S.E. Baranzini, T.L. Bugawan, O. Khan, et al. Mapping multiple sclerosis susceptibility to the HLA-DR locus in African Americans. Am J Hum Genet, 74, 160-7, 2004.

6) O. Olerup, and J. Hillert, HLA class II-associated genetic susceptibility in multiple sclerosis: a critical evaluation. Tissue Antigens, 38, 1-15, 1991.

7) C.F. Brosnan, L. Battistini, Y.L. Gao, C.S. Raine, and D.A. Aquino, Heat shock proteins and multiple sclerosis: a review. J Neuropathol Exp Neurol, 55, 389-402, 1996.

8) .A. Dyment, G.C. Ebers, and A.D. Sadovnick, Genetics of multiple sclerosis. Lancet Neurol, 3, 104-10, 2004.

9) C. Ballerini, E. Rosati, M. Salvetti, G. Ristori, S. Cannoni, T. Biagioli, et al. Protein tyrosine phosphatase receptor-type $\mathrm{C}$ exon 4 gene mutation distribution in an Italian multiple sclerosis population. Neurosci Lett, 328, 325-7, 2002. 
10) M. Jacobsen, D. Schweer, A. Ziegler, R. Gaber, S. Schock, and R. Schwinzer, A point mutation in PTPRC is associated with the development of multiple sclerosis. Nat Genet, 26, 495-9, 2000.

11) T. Vyshkina, T.P. Leist, Y.Y. Shugart, and B. Kalman, CD45 (PTPRC) as a candidate gene in multiple sclerosis. Mult Scler, 10, 614-7, 2004.

12) L.F. Barcellos, S. Caillier, L. Dragone, M. Elder, E. Vittinghoff, P. Bucher, et al. PTPRC (CD45) is not associated with the development of multiple sclerosis in U.S. patients. Nature Genet, 29, 23-24, 2001.

13) E. Cocco, M.R. Murru, C. Melis, L. Schirru, E. Solla, M. Lai, et al. PTPRC (CD45) C77G mutation does not contribute to multiple sclerosis susceptibility in Sardinian patients. J Neurol, 251, 1085-1088, 2004.

14) A.L. Szvetko, A. Jones, J. Mackenzie, L. Tajouri, P.A. Csurhes, J.M. Greer, et al. An investigation of the $\mathrm{C} 77 \mathrm{G}$ and $\mathrm{C} 772 \mathrm{~T}$ variations within the human protein tyrosine phosphatase receptor type $\mathrm{C}$ gene for association with multiple sclerosis in an Australian population. Brain Res 1255, 148$152,2009$.

15) I. Vorechovsky, J. Kralovicova, E. Tchilian, T. Masterman, Z. Zhang, B. Ferry, et al. Does 77C-G in PTPRC modify autoimmune disorders linked to the major histocompatibility locus? Nature Genet, 29, 22-23, 2001.
16) I.S. Trowbridge, and M.L. Thomas, CD45: an emerging role as a protein tyrosine phosphatase required for lymphocyte activation and development. Annu Rev Immunol, 12, 85-116, 1994.

17) A. Weiss, and D.R. Littman, Signal transduction by lymphocyte antigen receptors. Cell, 76, 263-74, 1994.

18) C.H. Polman, S.C. Reingold, B. Banwell, M. Clanet, J.A. Cohen, M. Filippi, et al. Diagnostic criteria for multiple sclerosis: 2010 revisions to the McDonald criteria. Ann Neurol, 69, 292-302, 2011.

19) M.A. Larkin, G. Blackshields, N.P. Brown, R. Chenna, P.A. McGettigan, H. McWilliam, et al. Clustal W and Clustal $\mathrm{X}$ version 2.0. Bioinformatics, 23, 2947-8, 2007.

20) J.D. Thompson, T.J. Gibson, F. Plewniak, F. Jeanmougin, and D.G. Higgins, The CLUSTAL_X windows interface: flexible strategies for multiple sequence alignment aided by quality analysis tools. Nucleic Acids Res, 25, 4876-82, 1997.

21) A. Ascherio, and K.L. Munger, Environmental risk factors for multiple sclerosis. Part I: the role of infection. Ann Neurol, 61, 288-99, 2007. 